\title{
Isolation of $\alpha$-Glucosidase Inhibitors From Soil Borne Aspergillus terreus and Cladosporium herbarum
}

\author{
Subedi $\mathrm{M},{ }^{1 *}$ Rajbhandari GS. ${ }^{2}$ \\ ${ }^{I}$ Department of Microbiology, Amrit Science College, Kathmandu, Nepal; ${ }^{2}$ Department of Botany, Amrit \\ Science College, Kathmandu, Nepal;
}

\begin{abstract}
Microorganisms and plants produce different novel compounds such as antibiotic, antitumor, cytotoxic, anti-inflammatory, etc. Many primary metabolites, such as amino acids, vitamins and nucleotides, which are capable of making secondary metabolites of microbes that, constitute half of the agriculture, industry and pharmaceuticals compounds with many essential products in the market today. $\alpha$-glucosidase inhibitors from the fungal origin would show potential inhibition to $\alpha$-glucosidase enzymes. These enzymes are involved in the breakdown of starch and other molecules containing polysaccharide components, such as the glycolipids and glycoproteins in biological membranes. This study was carried out with an aim to isolate $\alpha$-glucosidase inhibitors from fungi of different places of Nepal. The terrestrial soil samples were collected in sterile plastic bags from different places of Kathmandu, Pokhara and Nawalparasi during the month of May 2013 by random sampling method. In this study, twenty four fungi have been tested for production and primary screening of $\alpha$-glucosidase inhibitor. Among twenty four identified fungi, two fungi, Aspergillus terreus and Cladosporium herbarum produced more than $60 \%$ inhibition to $\alpha$-glucosidase enzyme. These organisms were found potential fungi to produce $\alpha$-glucosidase inhibitors in significant percentage and can be used for the further study.
\end{abstract}

Keywords: $\alpha$-glucosidase inhibitors, Aspergillus terreus, Cladosporium herbarum

\section{Introduction}

The $\alpha$-glucosidase enzymes are involved in the breakdown of starch and other molecules containing polysaccharide components, such as the glycolipids and glycoproteins in biological membranes (Fischer et al, 1995). $\alpha$-D-glucosideglucohydrolase (EC-3.2.1.20) is a membrane bound enzyme located at the epithelium of small intestine and key enzymes of carbohydrate metabolism and it catalyzes the hydrolysis of $\alpha$-glucosidic linkages which is the final step in the digestive process of carbohydrates. It cleaves $\alpha$-glucosidic linkage in holosides (oligo-saccharides) and in heteroside, their specificity is directed mainly towards the glucosidic residue which is represented by the radical $\alpha$-D-glucopyranosyl (Chen et al, 2004).

$\alpha$-glucosidase inhibitors such as acarbose, miglitol and voglibose are known to reduce postprandial hyperglycemia primarily by interfering with the carbohydrate digesting enzymes and delaying glucose absorption (Hsieh et al, 2010). $\alpha$-glucosidase inhibitors can be used either as monotherapy or in combination with other oral hypoglycemic agents or insulin. The use of $\alpha$-glucosidase inhibitors are considered i) for the treatment in a newly diagnosed diabetic patient, ii) for a patient of uncontrolled diabetes mellitus iii) alternative to sulphonylureas or biguanides in patients at risk from hypoglycemia or lactic acidosis respectively (Lhoret and Chiasson, 1998). Acarbose, one of the new classes of oral $\alpha$-glucosidase inhibitors, is a well-known, natural product produced by several species of Actinoplanes (Roboyt, 2005). It has been shown to be an effective inhibitor of several carbohydrases: $\alpha$-glucosidase (Schmidt et al, 1982), glucoamylase (Aleshin et al, 1994), cyclomaltodextringlucanyltransferase (CGTase), $\alpha$-amylase (Brzozowski and Davies, 1997), and dextransucrase (Kim et al, 1998).

Microbes have their potential to contribute to the health and well-being of people throughout the world. Instead of producing many primary metabolites, different microbes produce various secondary metabolites. The discovery of secondary metabolites goes 80 years back to the discovery of penicillin by Alexander Fleming (Roopesh et al, 2006). The novel compounds with various biological activities such as antibiotic, antitumor, cytotoxic, anti-inflammatory, etc. have been isolated and elucidated from different microbial and plant sources (Yoder, 2005). In case of fungal kingdom, endophytic fungi have their potential of $\alpha$-glucosidase inhibitory compounds (Munim et al, 2013). Colletotrichum sp have potential to act as antidiabetic agent, due to its inhibitory activity (Artanti et al, 2012). Aspergillus aculeatus is proved to have good $\alpha$-glucosidase inhibitory activity (Ingavat et al, 2009). Aspergillus oryzae has also been screened for development of $\alpha$-glucosidase inhibitory peptide (Kang et al, 2013).

Micromonospora sp. was reported for its efficient production of $\alpha$-amylase and $\alpha$-glucosidase inhibitors (Suthindhiran et al, 2009). Recently nine different endophytic fungi were isolated and evaluated for their potential to the $\alpha$-glucosidase inhibitoy activities (Mun'im et al, 2013). Production and the activities of different 
bioactive compounds of endophytic microbes are subjected to different ecological factors specially the temperature regimes of the growing media (Onifade, 2007). Besides, differential effects of ecological factors viz, temperature, growing period of the microbes etc play vital role on the production and the quality of different microbial products (Alvarez et al, 2015). However, studies on the potential of various soil borne endophytic isolates for $\alpha$-glucosidase inhibitoy activities from ecologically different habitats are not available. The general objectives of the present were to i) isolate and identify of the soil fungi, ii) screening of fungi for the production of $\alpha$-glucosidase enzyme inhibitors and identification of fungi with the highest inhibitor production and iii) purification of inhibitors, optimization of process parameters for inhibitor production.

\section{Materials and methods}

Soil samples were collected from Nawalparasi, Kathmandu and Pokhara. These three different locations were selected because of ecological and climatological variations. Nawalparasi is in the Lumbini District, western region state of Nepal and situated at the south west to Kathmandu valley at an altitude of 60$100 \mathrm{~m}$ from sea level. The Latitude of Nawalparasi is $27.64^{\prime} \mathrm{N}$ and the Longitude is $83.88^{\mathrm{E}} \mathrm{E}$, with hot tropical and sub-tropical climate. Kathmandu, the capital city of Nepal, is located at latitude $27^{\circ} 42^{\prime} \mathrm{N}$ and longitude at $85.4^{\circ} \mathrm{E}$. It is situated at an altitude of $1337 \mathrm{~m}$, with temperate climate. Average annual temperature of Kathmandu is $23^{\circ} \mathrm{C}-9^{\circ} \mathrm{C}$ and the wettest month is July with an average rainfall $325.3 \mathrm{~mm}$. Pokhara, the second largest city of Nepal, is located $200 \mathrm{~km}$ west of capital Kathmandu. The altitude varies from $780 \mathrm{~m}$ in the southern part to $1350 \mathrm{~m}$ in the north. The average highest temperature ranges from $19{ }^{\circ} \mathrm{C}-30.6{ }^{\circ} \mathrm{C}$ and the lowest $7-8^{0} \mathrm{C}$ during December-January. The highest precipitation is $940 \mathrm{~mm}$ during the month of July and minimum in $22 \mathrm{~mm}$ in December.

From different sites of Nawalparasi, Kathmandu, and Pokhara about 24 soil samples were collected randomly in sterile plastic bag and the bags were tightly stopped to prevent moisture loss. Total 24 soil samples were collected from three studied districts i.e., eight sites in each district. About half $\mathrm{kg}$ of soil from 4-5 different areas was collected from one site. From each site soil collected from four corners and one from the centre mixed. Total soil was divided into four equal halves of which two parts discarded and only two parts collected in a sterile plastic bag and brought them back to the lab for the further study. Soil properties of three different study areas are presented in Table 1.

Table 1. The characters of soil of different study areas

\begin{tabular}{|l|l|l|l|}
\hline \multirow{2}{*}{ Soil properties } & Study areas \\
\cline { 2 - 4 } & Nawalparasi & Pokhara & Kathmandu \\
\hline $\mathrm{pH}$ & $7.5-8$ & $5.5-6$ & $5.5-6$ \\
\hline Texture & Silt loam-Silt clay loam & Silt loam & Silt loam-clay loam \\
\hline Organic matters & $1.5-2.5 \%$ & $2.5-3.5 \%$ & $3.0-3.5 \%$ \\
\hline Nitrogen & $0.08-0.1 \%$ & $0.1-0.15 \%$ & $0.1-0.15 \%$ \\
\hline Potassium & $60-150 \mathrm{~kg} / \mathrm{hac}$ & $100-150 \mathrm{~kg} / \mathrm{hac}$ & $200-300 \mathrm{~kg} / \mathrm{hac}$ \\
\hline Phosphorus & $40-60 \mathrm{~kg} / \mathrm{hac}$ & $100-140 \mathrm{~kg} / \mathrm{hac}$ & $100-150 \mathrm{~kg} / \mathrm{hac}$. \\
\hline \hline
\end{tabular}

(Courtesy: The Department of Agriculture, NARC, Khumultar, Kathmandu).

Soil samples were stored at $4^{\circ} \mathrm{C}$ until processed. Enumeration of fungi from different soil samples was carried out using serial dilution and spread plate technique. The soil samples were serially diluted up to $10^{-5}$ fold, from each dilution $0.1 \mathrm{ml}$ of sample was pipetted into PDA medium plates following the spread plate technique for enumeration and isolation of fungi.

Serial dilution method is one of the common techniques to study soil organisms. In this method $9 \mathrm{ml}$ of water is added to $1 \mathrm{~g}$ of soil to get the dilution $10^{-1}$. From this dilution up to $10^{-5}$ were prepared. The plates were incubated at $28 \pm 1^{\circ} \mathrm{C}$ for 4-7 days for colony development. Soil was stored in $4^{0} \mathrm{C}$ until future study because soil from different site cannot be study at once.

The culture plates were incubated for 4 to 7 days at $28^{\circ} \mathrm{C}$. The plates were observed for growth, pigmentation and sporulation. After growth, the enumeration of fungal colony was performed. The characteristics like the structure and color of mycelia, shape and size of spores or conidia and sporangiophores or conidiophores were studied under the microscope. The fungal cultures isolated were named serially from N1N8, K1-K8 and P1-P8.Most of saprophytic fungi grows within seven days. Colonies of fast growing fungi appeared after $3^{\text {rd }}$ day of incubation. Some of plates were incubated up to 10 days when they did not show the spores after these were discarded. After the morphological and microscopic study of colonies, the identification was done by using reference slides and following standard book [Benson, (2002), Ellis, (1977), Ellis, (1985), Gilman, (1957), Rapper and Fennel, (1965), Rapper and Thom, (1945), Subramanian, (1971)].The identified fungi are presented in Table 2. The pigmented fungal cultures on PDA slants were observed for primary screening. All cultures were selected for the fermentation in Sabouraud Dextrose Broth (SDB) for the production of metabolite. For the screening of $\alpha$-glucosidase inhibitor from the secondary metabolites, cultures 
were subjected in small scale fermentation (submerged state fermentation). The inoculated broths were treated with rotary shaker incubator at $120 \mathrm{rpm}$ at $28^{\circ} \mathrm{C}$ for 7-8 days. After 7days of fermentation, the broth was used to extract inhibitor. Extraction was carried out with equal volume of ethyl acetate $(1: 1, \mathrm{v} / \mathrm{v})$ from each culture. After addition of ethyl acetate, the bottles were shaken at $250 \mathrm{rpm}$ for 2 hours at $28^{\circ} \mathrm{C}$ for extraction of the organic compounds. The organic layer was separated into aqueous layer by using separating funnel and Whatman's filter paper. The moisture was removed by adding anhydrous sodium sulphate to the organic solvent extract. The organic layer was filtered again and subjected to rotavapor at $30^{\circ}-40^{\circ} \mathrm{C}$ and allowed to dry completely and weight of the dried crude was measured and stored at $4^{\circ} \mathrm{C}$ in Eppendorf tube.

Thus, obtained crude extract was checked for $\alpha$-glucosidase inhibitor activity by re-dissolving in dimethyl sulfoxide to get a stock of $100 \mu \mathrm{g} / 10 \mu \mathrm{l}$ for $\alpha$-glucosidase inhibition assay. All the isolated pigmented pure fungal species were screened for $\alpha$-glucosidase inhibition activity by submerged state fermentation. Then $\alpha$-glucosidase inhibition was analyzed using kinetic end-point assay following the modified method of PistiaBrueggeman and Hollingsworth (Pistia-Brueggeman and Hollingsworth, 2001). In a 96-well plate reader, the yellow colour produced (due to $p$-nitrophenol formation) was quantitated by colorimetric analysis and reading the absorbance at $405 \mathrm{~nm}$. One unit of $\alpha$-glucosidase is defined as the amount of enzyme required for liberating $1 \mu \mathrm{M}$ PNP-nitrophenol per minute at $30^{\circ} \mathrm{c}$ under the standard assay conditions. $\lambda$-max of inhibitor was determined in the survey scan mode of the spectrophotometer in the range of 200 to $800 \mathrm{~nm}$. $100 \mu \mathrm{g} / 100 \mu \mathrm{l}$ in methanol was added to $100 \mu \mathrm{l}$ of the methanol in the 96 well plate reader and scanned from $200-800 \mathrm{~nm}$, using methanol as blank for all the samples.

\section{Result and Discussion}

The number of fungal colony forming units per gram of Nawalparasi soil was found to be $2.12 \times 10^{6}$ $\mathrm{CFU} / \mathrm{gm}$ which was higher than from the soil samples collected from Pokhara and Kathmandu. The CFU/gm of soil from Pokhara soil was $1.14 \times 10^{3} \mathrm{CFU} / \mathrm{gm}$ and from Kathmandu was found to be $2.35 \times 10^{4} \mathrm{CFU} / \mathrm{gm}$. This indicates that the soil population of fungi is highest in Nawalparasi soil and lowest in Pokhara soil. The temperature in Nawalparasi varies from very cold in winter to very hot in summer, so the occurrence in diversity of fungi is more. Similarly, in Kathmandu also, the winter temperatures goes below $7^{\circ} \mathrm{C}$ and in summer it reaches up to $33^{\circ} \mathrm{C}$ whereas in Pokhara, the temperature range is between $15^{\circ} \mathrm{C}$ to $37^{\circ} \mathrm{C}$ all the year round, so most of the fungi are of mesophilic range.

24 fungal cultures were selected for small scale fermentation. Some of the cultures produced very less extract and some produce good weight of extract. All the extracts were subjected for primary screening for $\square-$ glucosidase inhibitor production. P1, P2, P3, P4, P5, P6, P7, P8, N1, N2, N3, N4, N5, N6, N7, N8, K1, K2, K3, $\mathrm{K} 4, \mathrm{~K} 5, \mathrm{~K} 6, \mathrm{~K} 7$ and K8 cultures were selected for the fermentation in Potato Dextrose Broth for the production of metabolite. The highest production of metabolite was shown by $\mathrm{N} 4,17 \mathrm{mg} / 50 \mathrm{ml}$ and very less production by $\mathrm{K} 2,2 \mathrm{mg} / 50 \mathrm{ml}$ PDB. The morphology of colony was studied by observing the size, color and nature of colony, margin of colonies, presence or absence of moisture on the surface, pigmentation on front and back of the culture, presence or absence of concentric ring etc. Visual identification of spores in colony developed on selective media were done under low power, high power and oil immersion of the microscope by preparing the slides by Scotch tape preparation method (Table 2).

Table 2. List of identified fungi

\begin{tabular}{|l|l|}
\hline S. No. & Fungi \\
\hline 1 & Alternaria alternata \\
\hline 2 & Aspergillus flavus \\
\hline 3 & Aspergillus fumigatus \\
\hline 4 & Aspergillus niger \\
\hline 5 & Aspergillus sulfureus \\
\hline 7 & Aspergillus terreus \\
\hline 8 & Aspergillus versicolor \\
\hline 9 & Aureobasidium sp. \\
\hline 10 & Cladosporium cladosporoides \\
\hline 11 & Cladosporium herbarum \\
\hline 12 & Cladosporium sphaerospermum \\
\hline 13 & Cladosporium sp. \\
\hline 14 & Cunninghamella sp. \\
\hline 15 & Curvularia lunata \\
\hline 16 & Curvularia sp. \\
\hline 17 & Mucor sp. \\
\hline 18 & Penicillium expansum \\
\hline 19 & Penicillium humili \\
\hline 20 & Rhizopus niger \\
\hline
\end{tabular}




\begin{tabular}{|l|l|}
\hline 21 & Trichoderma horigianum \\
\hline
\end{tabular}

Fungal extracts from PDB for all showed only little or no inhibition except two P5 and K3 showed more than $60 \%$ inhibition. From the primary screening, no species of fungi showed the inhibitory effect, except K3 and P5 from Kathmandu soil and Pokhara Soil, were showing above 60\% inhibition for $\alpha$-glucosidase enzyme. All the cultures were again tested for SDB fermentation. From SDB, no culture showed significant inhibition. Results are presented Figure 1. However, the secondary screening for consistency in inhibition and crude production needs to be carried out.

These fungal cultures (K3 and P5) can be chosen for the further work and still more fungi need to be studied. Actinomycetes, usually isolated from terrestrial areas are known to be rich sources of novel and pharmaceutically important compounds. It has become evident that actinomycetes are the potential producers of various enzyme inhibitors (Bull \& Stach, 2007). In one study, the extract showed 64.1\% inhibition of $\alpha$ Amylase enzyme and $91.5 \%$ inhibition of $\alpha$-glucosidase at a concentration of $500 \mu \mathrm{g} \mathrm{mL}-1$ (Revathy et al, 2013). Micromonospora sp. VITSDK3 was reported for its efficient production of $\alpha$-amylase and $\alpha$-glucosidase inhibitors (Suthindhiran et al, 2010).

In the study of fungi, Cladosporium sp. have potential to act as anti-diabetic agent, due to its $\alpha$ glucosidase inhibitory (Artanti et al, 2012). Aspergillus aculeatus is proved to have good $\alpha$ - glucosidase inhibitory activity (Ingavat et al, 2009). Since in our results, these fungi (Aspergillus terreus and Cladosporium herbarum) were capable of producing above $60 \%$ inhibition for $\alpha$-glucosidase enzyme. The remaining cultures from other soil samples also need primary screening. Besides all the cultures need to be checked for crude production and enzyme inhibition by solid state fermentation also.The highest production of metabolite was shown by N5, $22 \mathrm{mg} / 50 \mathrm{ml}$ SDB. The less amount of crude was produced by N1, 3mg $/ 50 \mathrm{ml} \mathrm{SDB}$. The inhibition percentage of above $50 \%$ was not shown by any culture (Figure 1).

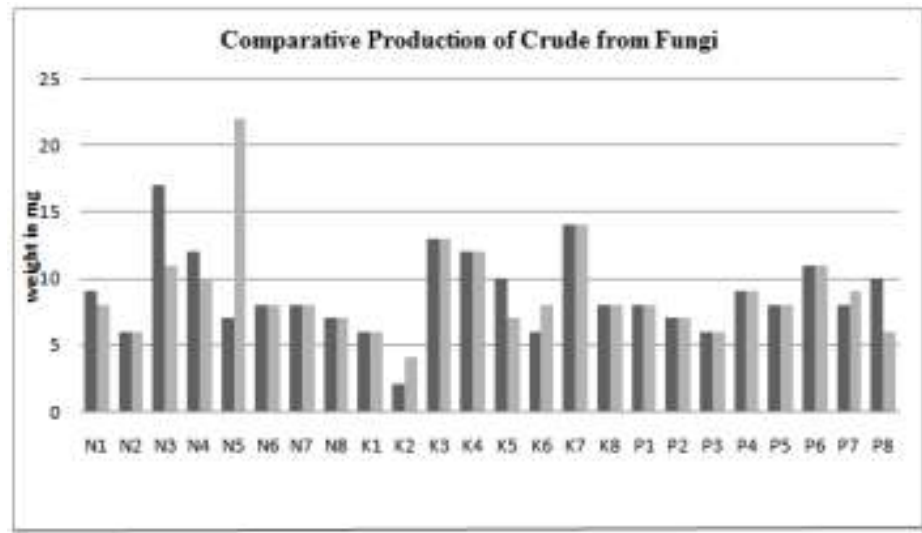

Figure 1: Comparative production of crude from PDB and SDB (mg per $50 \mathrm{ml}$ media).

The inhibition shown by the crude produced from SDB was different from the inhibition shown by the crudes of same fungi from the PDB. Though the crude production was higher, none of the tested organism showed significant inhibition from the metabolites of SDB fermented media which is shown in Figure 2.

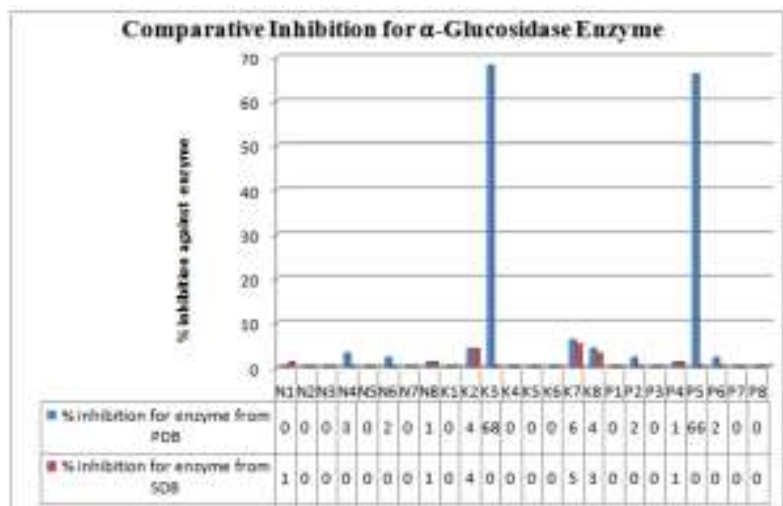

Figure 2: Comparative Inhibition for $\alpha$ - glucosidase enzymes

The $\lambda_{\max }$ value of the crude compound was determined by using $100 \mu$ l of methanol as blank, and $100 \mu \mathrm{g}$ crude per $10 \mu \mathrm{l}$ of methanol $(100 \mu \mathrm{g} / 10 \mu \mathrm{l})$ in $100 \mu \mathrm{l}$ methanol. The wavelength range $(\mathrm{nm})$ was determined at 
medium scan speed for 3 minutes with $200 \mathrm{~nm}$ to $800 \mathrm{~nm}$ range. $\lambda_{\max }$ profile of all the extract compounds were determined. The $\lambda_{\max }$ profile for K3 shows maximum absorbance at around 340nm, and for p5 shows around $350 \mathrm{~nm}$. These two fungal extracts show maximum absorbance between 320 to $360 \mathrm{~nm}$ (Figure 3 and Figure 4).

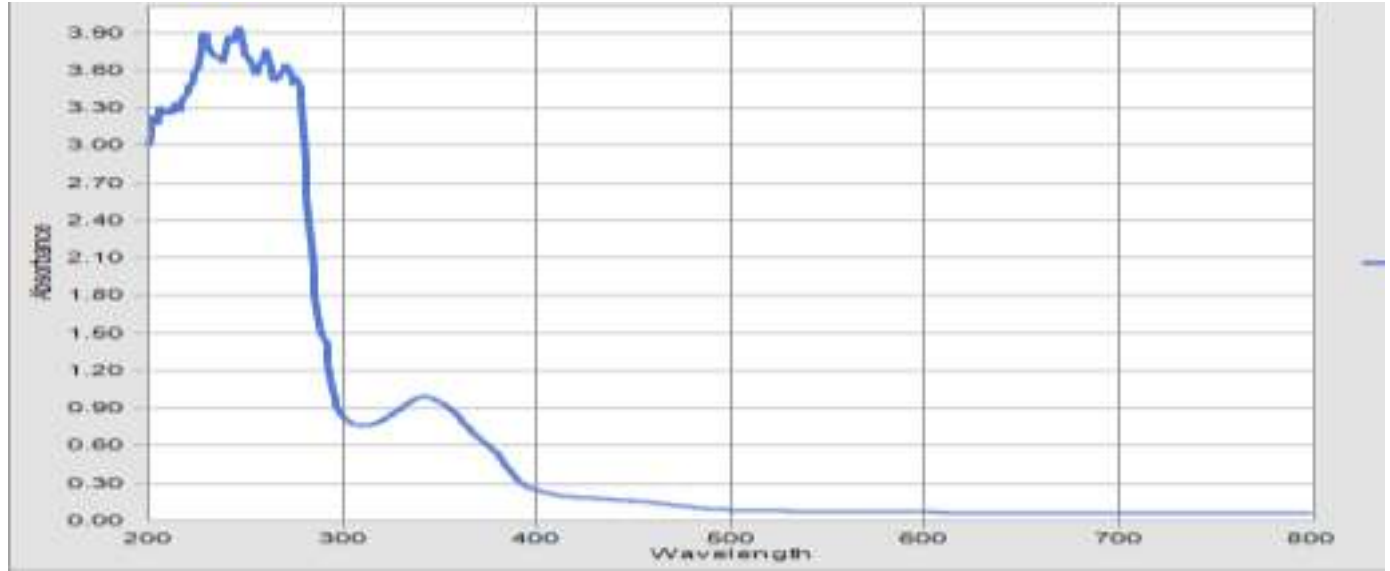

Figure 3: $\lambda_{\max }$ curve for K3 showing absorbance around 350nm.

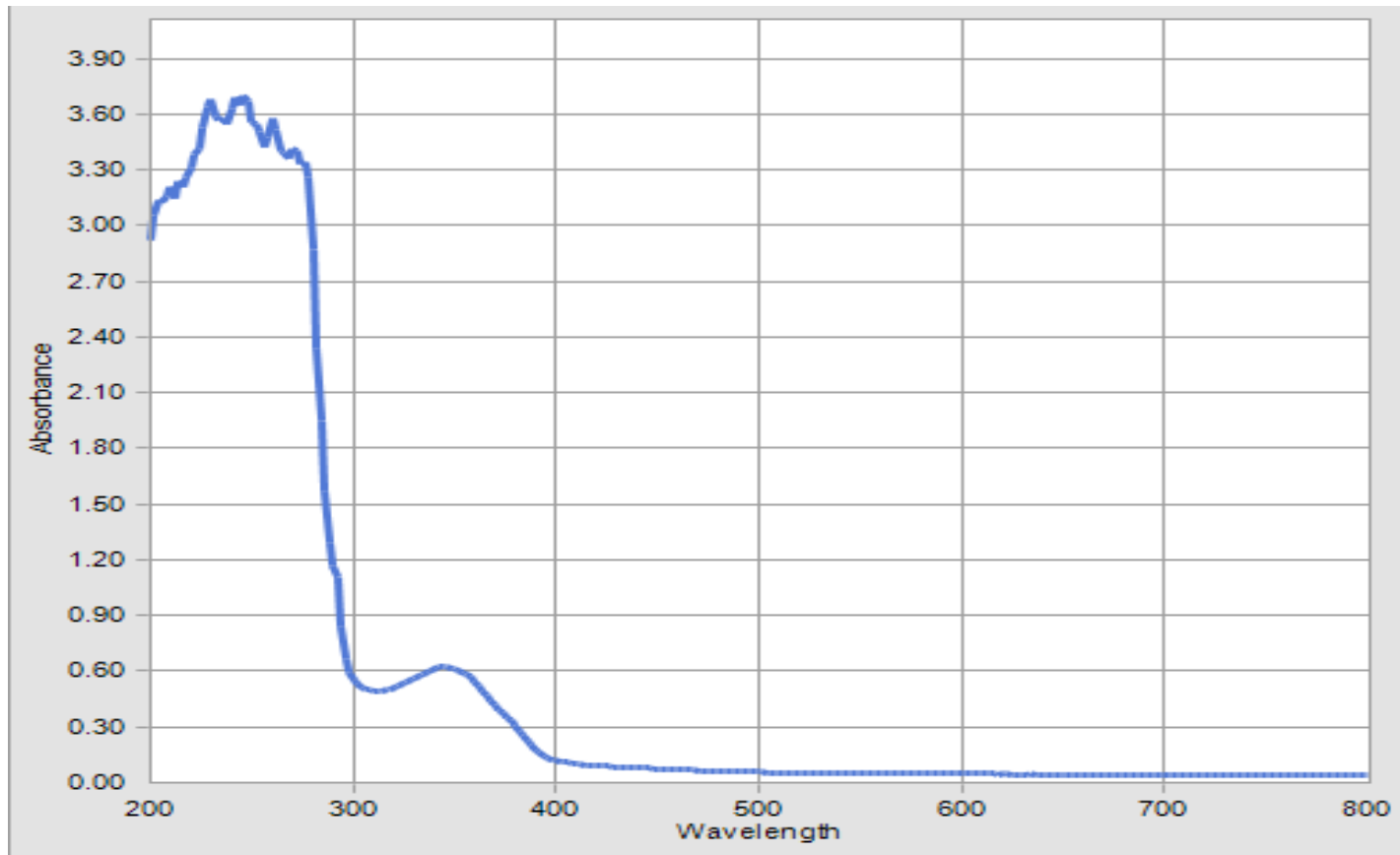

Figure 4: $\lambda_{\max }$ curve for P5 showing absorbance around 350nm.

\section{Conclusion}

Marine microorganisms are known to produce various novel metabolites. Among microorganisms, Actinomycetes are the largest producer of secondary metabolites. Comparison to this, little research has been carried out in fungi. In the present study, different around 40 fungi were isolated from different terrestrial soil samples and 24 of them were used for the production of $\alpha$-glucosidase inhibitor and these fungi were identified by using standard protocol. Two strains of fungi, Aspergillus terreus and Cladosporium herbarum produced $\alpha-$ glucosidase inhibitors in significant percentage. These fungi can be used further research and the compound produced from these can be characterized and graded. Further work can be done like molecular diagnosis of fungal strain and if necessary strain improvement techniques can also be adapted.

\section{Acknowledgement}

Authors thank University Grants Commission (UGC), Nepal for providing financial assistance to conduct this research. 


\section{References}

[1.] Alvarez MA, Ponce AG, and Moreira MR, 2015. Combined Effect of Bioactive Compounds and Storage Temperature on Sensory Quality and Safety of Minimally Processed Celery, Leek and Butternut Squash. Journ. Food Saf., Volume 35, Issue 4, pp 560-74.

[2.] Artanti N, Tachibana S, Kardono LB, Sukiman H, 2012. Isolation of $\boldsymbol{\alpha}$-glucosidase inhibitors produced by an endophytic fungus, Colletotrichum sp. TSC13 from Taxus sumatrana. Pak J Biol Sci. Jul $15 ; 15(14): 673-9$.

[3.] Aleshin AE, Firsov LM, Honzatko RB, 1994. Refined structure for the complex of acarbose. $J$ Biol Chem. Jun 3;269(22):15631-9. PubMed PMID: 8195212.

[4.] Benson JH, 2002. Microbiological Applications A Laboratory Manual in General Microbiology. $8^{\text {th }}$ Edition, The McGraw-Hill Companies pp.201-202.

[5.] Brzozowski AM, Davies GJ, 1997. Structure of the Aspergillus oryzae alpha-amylase complexed with the inhibitor acarbose at 2.0 A resolution. Biochemistry. Sep 9;36(36):10837-10845.[PubMed]

[6.] Bull AT, Stach J, 2007. Marine actinobacteria: new opportunities for natural product search and discovery. Trends in Microbiology, 15(11), 491-499.

[7.] Chen H, Yan Y, Lin W, Zheng L, Zhang L, 2004. A New Method for Screening $\alpha$-Glucosidase Inhibitors and Application to Marine Microorganisms. Taylor and Francis Ltd. Pharm. Biol. Int. J. of Pharmacology, 42, (6) 416-421.

[8.] Ellis MB, 1977, Dematiaceous hypomycetes, Common Wealth mycological Institute. Kew Survey, England.

[9.] Ellis MB, 1985. More Dematiaceous hypomycetes Common Wealth mycological Institute, Kew Survey England.

[10.] Fischer PB, Collin M, Karlsson GB, James W, Butters TD, Davis SJ, Gordon S, Dwek RA, Platt FM, 1995. The $\square$-Glucosidase Inhibitor $N$-Butyl-deoxynojirimycin inhibits Human Immunodeficiency virus entry at the level of post-CD4 binding. $J$ of Virol. 69, 5791-5797.

[11.] Gilman JC, 1957. A manual of soil fungi. Oxford and IBH publishing Co.,

[12.] Hsieh PC, Huang GJ, Ho YL, Lin YH, Huang SS, Chiang YC, Tseng MC, Chang, YS, 2010. Activities of antioxidants, $\alpha$-Glucosidase inhibitors and aldose reductase inhibitors of the aqueous extracts of four Flemingia species in Taiwan. Biochem. 51, 293-302.

[13.] Ingavat N, Dobereiner J, Wiyakrutta S, Mahidol C, Ruchirawat S, Kittakoop P, 2009. Aspergillusol A, an $\alpha$-Glucosidase inhibitors from marine derived fungus Aspergillus aculeatus. Journal of Natural Products 72:2049-2052.

[14.] JoS H, Ha KS, Moon KS, Lee OH, Jang HD, Kwon YI, 2011. In Vitro and in Vivo AntiHyperglycemic Effects of Omija (Schizandrachinensis) Fruit. Int. J. Mol. Sci., 12, 1359-1370.

[15.] Kang MG, Yi SH, Lee JS, 2013. Production and characterization of a new $\square$-glucosidase inhibitory peptide from Aspergillus oryzae N159-1. Mycobiology, 41(3): 149-154.

[16.] Kim D, Park KH, Robyt JF, 1998. Acarbose effect for dexran synthesis, acceptor and disproportionation reactions of Leuconostoc mesenteroides B-512FMCM dextransucrase. $J$. Microbiol. Biotechnol. 8, 287-290.

[17.] Lhoret R, Chiasson JL, 1998. Potential of alpha-glucosidase inhibitors in elderly patients with diabetes mellitus and impaired glucose tolerance. Drugs Aging. 13(2):131-43.

[18.] Munim A, Ramadhan MG, Soemiati A, 2013. Screening of Endophytic fungi from Cassia Siamea lamk leaves. Int.Res. J.Pharm. 4 (5).

[19.] Onifade AK, 2007. Research trends: Bioactive metabolites of fungal origin. Journal of Biological Sciences, 2: 81-84.

[20.] Pistia-Brueggeman G, Hollingsworth RI, 2001. A preparation and screening strategy for glycosidase inhibitors. Tetrahedron, 57:8773-8778.

[21.] Rapper KB \& Fennel, DI 1965, The genus Aspergillus, The William \& Wilkins Co., Baltimore

[22.] Rapper KB, Thom, CA, 1945. A Manual of the Penicillium, The William \& Wilkins Co., Baltimore.

[23.] Revathy T, Jayasri MA, Suthindhiran K, 2013. Anti-oxidant and enzyme-inhibitory potential of marine Streptomyces. American Journal of Biochemistry and Biotechnlogy. 9 (3), 282-290.

[24.] Robyt JF, 2005. Inhibition, activation, and stabilization of $\alpha$-amylase family enzymes. Biologia, Bratislava, 60/Suppl. 16, 17-26.

[25.] Roopesh K, Ramachandran S, Nampoothiri KM, Szakacs G, Pandey A, 2006. Comparison of the Phytase production on wheat bran and oilcakes in Solid State fermentation by Mucorracemosus. Bioresour. Technol. 97(3), 506-511.

[26.] Schmidt DD, Frommer W, Junge B, Ller LM, Wingender W, Truscheit E, 1982. In: Creutzfeldt, W. First International Symposium on Acarbose, Excerpta Medica, Amsterdam, 5-15. 
[27.] Subramanian CV, 1971, 'Hypomycetes-An account of Indian species, except Cercosporae', Indian council of Agricultural research, New Dellhi.

[28.] Suthindhiran K, Kannabiran K, 2010. Hemolytic activity of Streptomyces VITSTDK1 sp. isolated from marine soil in southern India. $J$. Med. Mycol., 19, 77-86.

[29.] Suthindhiran KR, Jayasri MA, Kannabiran K, 2009. $\alpha$-glucosidase and $\alpha$-amylase inhibitory activity of Micromonospora sp. VITSDK3 (EU551238). Int. J. Integ. Biol., 6, 115-120.

[30.] Yoder BJ, 2005. Isolation and structure elucidation of cytotoxic natural products from the rainforests of Madagascar and Suriname.PhD Thesis. Blacksburg, Virginia, USA. 